\title{
Contribution of the Information Technology Audit in Achieving the Quality of the Electronic Accounting System: Evidence from the Algerian Banking Sector
}

\author{
Mostéfaoui Sofiane ${ }^{1}$, Hamimeche Nardjes ${ }^{1}$, Akacem Omar ${ }^{2}$ \\ ${ }^{1}$ Department of Management Sciences, University of Adrar, Adrar, Algeria \\ ${ }^{2}$ Laboratory of Afro-Algerian Economic Integration, University of Adrar, Adrar, Algeria \\ Email address: \\ moste20@yahoo.fr (M. Sofiane), hamimeche_nardjes@hotmail.com (H. Nardjes), ooakacem2007@yahoo.fr (A. Omar)
}

\section{To cite this article:}

Mostéfaoui Sofiane, Hamimeche Nardjes, Akacem Omar. Contribution of the Information Technology Audit in Achieving the Quality of the Electronic Accounting System: Evidence from the Algerian Banking Sector. International Journal of Economics, Finance and Management Sciences. Vol. 4, No. 2, 2016, pp. 46-51. doi: 10.11648/j.ijefm.20160402.12

\begin{abstract}
The banking sector occupies a central position in the economy. This consideration stems from the roles and the responsibilities assumed by this institution. Therefore, the consolidation of the system comprising the banking and other financial institutions by all kinds of technology and information becomes more than a necessity in an attempt to improve the quality of the services provided in one hand and to strengthen the banking organization per se at the other. The latter objective is ensured by different mechanisms. One of these is the auditing mechanism. The paper sheds light on the impact of the information technology audit in increasing the quality of the bank accounting system. The study shows that the acquisition of the modern technology is not based only on feasibility, but in response to the requirement of the competition and the customers' satisfaction.
\end{abstract}

Keywords: Audit, Information Technology System, Electronic Accounting System, Algerian Banking Sector

\section{Introduction}

The banking sector is a pivotal component of the economy. This importance stems from the fact that it ensures channeling funds between individuals and firms (William M. Gouge 1968; Andrew F. Brimmer 1971; Lars G. Sandberg 1978; Philip Arestis, Panicos O. Demetriades, Kul B. Luintel 2001; Been-Lon Chen 2006; Frederick Mishkin, Kent Matthews, Massimo Giuliodori 2013). It is by this sense considered as one of the four basic compartments of the economic institutions: the material exchange department (ensuring the flows of diverse items and services between agents), the security exchange department (ensuring the required safety to deal the business activities), the institutional department (package of various jurisdictions and laws that regulate and organize the procedures of the economic activities) and the financial department (flows of financial assets and the necessary payment means to engage effectively in business operations).

The banking sector had benefited from the integration of the technology techniques and processes in various aspects of its operations and activities. The purpose of this adoption is to save time, effort and having a good reputation (Edwin Nixon 1986; J. Yannis Bakos, Michael E. Treacy 1986; Blake Ives, Sirkka L. Jarvenpaa, 1991; Vary T. Coates 1992; Erik Brynjolfsson 1994; Robert Hauswald, Robert Marquez 2003; D. Seese, C. Weinhardt, F. Schlottmann 2008). The context of technology is widely used as the services are provided in electronic form within the framework of the so-called e-banks (Rupa Rege Nitsure $2003,2004)$. In addition to this, the accounting information systems took their part in the technology usage by the different electronic treatments and analyses of the accounting information (António Trigo, Fernando Belfo, Raquel Pérez Estébanez 2014; Andreas Hellmann 2016).

These new electronic techniques provide huge and considerable opportunities to the financial institution by increasing the chance to benefit from the historical and actual financial and non financial statements in order to use them for the rationalization of the managers' decision making (Carl Shapiro and Hal R. Varian 1999). Besides, the technology process paves the way for a good management of the informational stock held by the organization. 
Regarding the advantages offered by the use of accounting information to the electronic bank systems, it will be worthwhile to continually evaluate the performance of these systems in order to maintain the stability of their performance and to correct their imbalances in such a way to preserve their quality. In this context, our research aims to identify the role of the information technology audit in the concretization of the quality standards relation to the banking information system.

\section{The Information Technology Audit}

The information technology audit means the process of collecting and evaluating the proofs and statements in order to determine the contribution the computer in preserving the firm's assets and safeguarding the accuracy of its data. This technical usage leads to realize efficiently the objectives of the firm and increases the rationality level of its resources exploitation. To achieve the targets, the auditor verifies the existence of two important systems (Hemantha S. B. Herath, Tejaswini C. Herath 2014; Emil Papazov, Lyudmila Mihaylova 2015):

- A suitable information system which provides the accounting information for the efficient preparation of the consolidated reports and the sound systems.

- An effective system of internal controls which prevent the errors and the irregularities or diminish them to the lowest level.

\section{The Objectives and Importance of Auditing IT Systems}

The international Standard N 401 issued by the international Federation of Accountants had denoted that there is no way to change the audit objectives stated previously whether the accounting data are treated manually or electronically by computers (Nurten Erdogan, Sezen Uludag 2014; Loan Rus 2015). However, the electronic usage (computers) is able to realize more objectives as:

- Ensure that the use of computers is in the Service Corporation and at the lowest possible cost, and provides the appropriate information in a timely manner, which is beneficial to the institution;

- Checking the effectiveness of the regulatory tools to ensure the efficiency of the internal control system in all administrative, financial and operational activities;

- Checking the relative importance of the computer service in the institution, the fact that leads to the realization of the most important requirements for the enterprise;

- Ensure the protection of information systems from various risks resulting from the use or deliberate omission.

The responsibility of the auditor to demonstrate the appearance of false or faked information in the financial statements requires the sufficient awareness of the auditor himself and a good understanding of the various systems adopted. The aim of these two important qualities is to reach an acceptable level of confidence letting him to express assertively his opinion about the financial situation of the enterprise (Ol'ga Ponisciakova, Martina Gogolova, Katarina Ivankova 2015). In this context, the International Standard N 401 had stated that the auditor should acquire sufficient knowledge of the environment of information technology system for the purpose of planning, managing, supervising and inspecting the work performed (Denise Dickins, Rebecca Fay and Brian Daugherty 2015). At this point, the auditor has to decide whether there is a need to use specialized skills in the field of information technology.

\section{Standards of IT Systems Auditing}

The association of Auditing and Controlling the Information Technology Systems had focused on the importance of standards establishment that organize the information technology auditing system (K. H. Spencer Pickett 2003; Massood Samii and Gerald Karush2004; Igor Balaban, Enrique Mu, Blazenka Divjak 2013; Hemantha S. B. Herath, Tejaswini C. Herath 2014). In this field, the association called for the institution of an audit charter which clarifies the functions and prerogatives of the auditing. In addition, it advocated the necessity as well as the obligation of the auditor to be fully independent and he must enjoy the ethics standards and the required skills to assume adroitly his responsibilities. Moreover, the international standards of the internal auditing stressed the importance of technology possession for the auditor in order to facilitate the auditing task. Through these standards, it is clear that the auditor' work requires:

- The auditor involvement in the development of the institution and the evaluation of existing plan according to the continual changes of the organization;

- The auditor involvement in the development of systems and providing the tips with regard to the specificities of the projects and the minimization of the risks;

- The evaluation of the information technology in the organization to see how they are consistent with the goals of the organization and structure, and the effectiveness of dealing with risk;

- The provision of the training and the awareness about the risks of information technology and the provision of the best regulatory practices and procedures based on the best practices derived from information security issues;

- The auditor involvement in the risk assessment with the other departments in the organization (human resources, legal affairs and risk management...) to ensure the appropriateness of audit plans and strengthen the roles with regard to risk assessment;

- The inventory of IT assets in the enterprise in an attempt to evaluate the risks and to follow the model in such a way to determine the classification of information technology-related projects, infrastructure, and software risks... 


\section{Stages of Information Technology Auditing}

The information technology auditing passes by the following stages (Vadlamani Ravi 2008):

- The previous control of the input: at this stage, the auditor investigates the documentary sessions, follows the flow of data through the documents and he ascertains that it fulfill the conditions demanded.

- Auditing and reviewing the data used by the computer: reviewing the documents leads to verify the data submitted to the department of electronic data processing. This stage ensures the safety of the information required in time of data exploitation (Hemantha S. B. Herath and Tejaswini C. Herath2014).

- Controlling the computer programs used in the operation of the data, analysis and presentation of information: this control takes into consideration the computer program design, the computer safety performance, the suitability of the orders and instruction from an accounting perspective, the presence of self-control tools within the program and the accuracy of the modifications integrated to the program.

- Another way to guarantee the safety of the computer program is by comparing the results obtained from the computer data processing by the same data treated manually.

- Controlling the information output and the ways of presentation and interpretation: the auditor at this stage matches the actual output with the results to be obtained from the design and the reality perspective (Fiona Ball, Jonathan Tyler, and Peter Wells 2015; Gary P. Braun, Christine M. Haynes, Tom D. Lewis and Mark H. Taylor 2015). He makes sure that the interpretation of a document by the accountant is correctly based on correct and accurate numbers issued by the computer so as to avoid any sort of manipulation or falsification in the information interpretation.

\section{The Electronic Accounting Information System}

The accounting information system is a sub-system that works and interacts independently and mutually with the other systems in order to provide historical information, current and future financial and non-financial data in an attempt to serve the objectives of the economic organization.

Also it is defined as a network of actions associated with each other and governed by the principles, sound rules, and appropriate manner of preparation in order to provide information and data to the decision-maker properly.

Thus, the accounting information system is a computerized system adopted to provide appropriate information for decision-makers. The e-system obliges the accountant to be familiar with the capacity and the possibilities of the computer in which data are entered.

\section{Advantages of Electronic Accounting Information System in the Banking Sector}

The advantages of electronic accounting information systems in banks are stated as follows:

- Accuracy and speed in the preparation of documents, calculations and implementation of accounting procedures, which in turn lead to save time and effort, reduce the size of computational errors, and decrease the bank's costs (K. H. Spencer Pickett. (2003);

- Improve the treatment process of the accounting books and documents and facilitate the collection, storage and data retrieval in the form of information (K. H. Spencer Pickett. (2005);

- The speed of the completion of similar operations at one time and the record of a large number of accounting operations, and the use of a smaller number of individuals in a short time;

- Tighten the internal and the self control on the implementation of operations, so that they can avoid the mistakes in the various operating stages, achieving precision in the extraction of information and the final results (Ol'ga Ponisciakova, Martina Gogolova and Katarina Ivankova 2015). These objectives are possible only by the capacity of the computer to adjust, control and verify of the results which enable the efficient management of the processes;

- Increase the confidence in the information generated by the computer electronic operation displayed in the reports, so that can be used by decision-makers as the basis for a sound and reliable decision-making;

- Improve the control and decision-making processes by increasing the efficiency of management control systems and providing the relevant information and reports, in addition to the speed of delivery of feedback decisions resulting from the information;

- To provide full flexibility in the design of accounting information systems through the storage and retrieval of information in a timely manner, because it contains a sophisticated database;

- The application of knowledge and mating other methods such as: operations research methods, which in turn help to create an integrated system of accounting and management information, and open new horizons for scientific research and practical studies.

\section{Quality of the Information System Factors}

In order to increase the quality of the information system, the auditor should check that the system includes the various functions and objectives in the organization. This system 
should be reliable, feasible, available and meets the needs of the users in a timely manner (Susan M. Switzer 2007). In this context, the information generated by the information system should be:

- Appropriate which enjoys a predictive or a sure value or both of them and is available in a timely manner;

- Descriptive, comprehensive, neutral and free of errors;

- Comparable which requires the stability of the analysis methods;

- Verifiable;

- Rapidity in producing the information to reach its targets;

- Understandable, which requires to be well presented (Victoria Chiu, Qi Liu and Miklos A. Vasarhelyi 2014);

- The cost of obtaining the information should be less than its expected return.

\section{Empirical Study}

\subsection{Study Methodology}

The study was conducted through a questionnaire addressed to accountants, internal and external auditors, and managers to learn and analyze their assessment of the role of the information technology auditor in achieving high quality of the information system. Data are analyzed by using SPSS software.

The sample consisted of 47 individuals; their answers were conducted through LIKERT scale based on five scales to determine the sample answers. Scale five denotes totally accepted while the scale 1 means totally rejected.

Questionnaire was also subjected to ALPHA test to check its consistency. ALPHA indicator equals 0.89 which is an acceptable value indicating the stability of the questionnaire and its suitability with the target.

Table 1. The sample consisted of.

\begin{tabular}{llll}
\hline \multirow{2}{*}{$\begin{array}{l}\text { The distribution of } \\
\text { respondents by }\end{array}$} & Profession & Number & Percentage (\%) \\
\cline { 2 - 4 } profession & Auditor & 18 & $38 \%$ \\
& Accountant & 19 & $41 \%$ \\
& Manager & 10 & $21 \%$ \\
\hline
\end{tabular}

Source: prepared by researchers based on the outputs of SPSS program

\subsection{The Availability of the Requirements Concerning the Quality of the Electronic System}

In this section we surveyed the opinions of the studied sample about the most important properties of the electronic information system are surveyed and classified according to their importance in supporting the process of the information technology auditing.

Table 2. Paragraph 01: the quality of the electronic accounting information system requires that the cost of the information resulting from the system should be reliable and verifiable.

\begin{tabular}{lll}
\hline Mean & Standard Deviation & Rank \\
\hline 4.58 & 0.80 & 01 \\
\hline
\end{tabular}

Source: prepared by researchers relying on SPSS output
According to the interviewer sample, the reliability of the accounting information system is the most important property sought to be provided by the bank.

The reliability requires, according to the statement No. 02 of the Council of accounting standards that the full information should be impartial and free of errors and have been applied without errors. In this area the internal auditor supports the reliability of the information generated by ensuring the availability of supporting documents for operations prior to their integration procedures in the system, in addition to screening the programs in such a way to ensure the safety outputs.

This role is supported by the scientific skills and the experiments conditioned by the Audit International Standard. The standards require the audit being updated by the necessary acquaintances I the field of accounting, information technology... to consolidate and improve the quality of his responsibilities. This condition makes the auditor able to detect well the errors and correct the imbalances in the system, the fact that ensures the possibility for the output to be verified by another party.

Table 3. Paragraph 02: the quality of electronic accounting information system requires the rapidity and swiftness of the information transmission to the user.

\begin{tabular}{lll}
\hline Mean & Standard Deviation & Rank \\
\hline 4.23 & 0.98 & 02 \\
\hline
\end{tabular}

Source: prepared by researchers relying on SPSS output

The rapidity and the swiftness of the information transmission occupy the second position in the priority scale of the sample reviewed. This is because the transmission time of the information impacts its relevance and usefulness in decision making process. Furthermore, the confusion in this context is between the rapidity of the system to produce the data rather than focusing on the reliability or to widen the procedures of relevance which takes much more time affecting the timeliness of the information access.

In this context, the audit of the information technology systems ensures the compatibility between the reliability and the rapidity of the accounting system outputs. The compatibility target is achieved by the contribution of the system itself to establish an efficient system of internal audit that improves the information production process without affecting its reliability.

Table 4. Paragraph 03: the quality of the electronic accounting information system requires that the cost of producing the information should to be less than its return.

\begin{tabular}{lll}
\hline Mean & Standard Deviation & Rank \\
\hline 4.08 & 1.18 & 03 \\
\hline
\end{tabular}

Source: prepared by researchers relying on SPSS output

The cost as a criterion occupies the third position in the concern of the respondents. It is assumed that the costs are justified and have their compatible returns. These costs include the costs to acquire the input and the programs as well as its development processes. This item holds also all 
kinds of various costs related to the usage maintaining and the usage of the information.

The cost / benefit analysis is the most important elements to be studied for the reason that the benefit resulting from the financial information is a personal consideration. The latter varies from one user to another on the one hand, and the cost of producing the information is incurred by the institution in which the benefits of the financial statements are shared among various users.

Information technology auditor-especially the internal auditor-seeks to increase the efficiency in the various activities and functions in addition to reduce costs by ensuring tighter control of them and enhancing the division of labor. In this area, the good system should avoid any unimportant information which leads to an increase of the establishment and the process of the system.

Table 5. Paragraph 04: the quality of the accounting information system requires the comparison of the information.

\begin{tabular}{lll}
\hline Mean & Standard Deviation & Rank \\
\hline 4.02 & 0.86 & 04 \\
\hline
\end{tabular}

Source: prepared by researchers relying on SPSS output

The comparison eligibility means that the user of the financial information compares between two alternatives or more to detect the best one for decision making process.

Table 6. Paragraph 05: the quality of the electronic accounting information system requires the control and the management of the risks.

\begin{tabular}{lll}
\hline Mean & Standard Deviation & Rank \\
\hline 3.95 & 0.8 & 05 \\
\hline
\end{tabular}

Source: prepared by researchers relying on SPSS output

The reliability of the accounting information electronic systems leads to the performance stability in information processing, but in return produces a range of risks associated with the operation data and programs, fake the loss of the operation process which increases the probability of error and the information manipulation.

\section{Conclusion}

This study aims to clarify the role of the auditor under the automatic processing of the information in realizing the quality standards of the electronic information for Algerian bank users.

The investigation also show the interest of the users by the quality characteristics in the electronic systems in an attempt to reach such a level of reliability of the accounting system outputs as well as the control and the management of the risks incurred by these systems.

The empirical study of the Algerian financial institution reveals that the acquisition of the modern technology is not based only on feasibility, but in response to the requirement of the competition and the customers' satisfaction as the operation of systems do not accompany the continuous measurement of the value, which is a flaw in the information technology governance system in the organization.

The study also shows that the role of the technology information audit in achieving the quality of the accounting system is important as it affords the necessary skills and experiments to detect errors, evaluate risks and the contribution in the design of the reduction risks procedures in order to benefit from the in the decision making processes.

\section{Acknowledgement}

The authors express their warm thanks to all the bank agencies in Adrar town for the experiment survey. They also thank the laboratory of the Afro-Algerian Integration of Adrar University for the help and the encouragement to accomplish this work

\section{References}

[1] Andrew F. Brimmer. (1971), Central Banking and Economic Development: The Record of Innovation, Journal of money, Credit and Banking 3(4): 780-792

[2] Andreas Hellmann. (2016), The Role of Accounting in Behavioral Finance, Journal of Behavioral and Experimental Finance 9: 39-42

[3] António Trigo, Fernando Belfo and Raquel Pérez Estébanez. (2014), Accounting Information Systems: The Challenge of the Real-Time Reporting, Procedia Technology 16: 118-127

[4] Been-Lon Chen 2006, Economic Growth with an Optimal Public Spending Composition, Oxford Economic Papers 58 (1): $123-136$

[5] Blake Ives and Sirkka L. Jarvenpaa 1991, Applications of Global Information Technology: Key Issues for Management, MIS Quarterly 15(1): 33-49

[6] Carl Shapiro and Hal R. Varian. (1999), Information Rules: A Strategic Guide to the Network economy, Harvard Business School Press, Boston Massachusetts

[7] D. Seese, C. Weinhardt and F. Schlottmann. (2008), Handbook of Information Technology in Finance, Springer-Verlag Berlin Heidelberg

[8] Denise Dickins, Rebecca Fay and Brian Daugherty. (2015), For Better or Worse: A Study of Auditors' Practices Under Auditing Standard No. 7, Research in Accounting Regulation 27: 174-186

[9] Edwin Nixon 1986, Information Technology: The Way Ahead, The Journal of the Operational Research Society 37(1): 1-11

[10] Erik Brynjolfsson 1994, Information Assets, Technology, and Organization, Management Science 40(12): 1645-1662

[11] Emil Papazov and Lyudmila Mihaylova. (2015), Organization of Management Accounting Information in the Context of the Corporate Strategy, Procedia - Social and Behavioral Sciences 213: 309-313

[12] Frederick Mishkin, Kent Matthews, Massimo Giuliodori 2013, The Economics of Money, Banking and Financial Markets European Edition, Pearson Education 
[13] Hemantha S. B. Herath and Tejaswini C. Herath. (2014), IT Security Auditing: A Performance Evaluation Decision Model, Decision Support Systems 57: 54-63

[14] Igor Balaban, Enrique Mu and Blazenka Divjak. (2013), Development of an Electronic Portfolio System Success Model: An Information System Approach, Computers and Education 60: 396-411

[15] J. Yannis Bakos and Michael E. Treacy 1986, Information Technology and Corporate Strategy: A Research Perspective, MIS Quarterly 10(2): 107-119

[16] K. H. Spencer Pickett. (2003), The Internal Auditing Handbook, second edition, John Wiley \& Sons, Inc

[17] K. H. Spencer Pickett. (2005), Auditing the Risk Management Process, John Wiley \& Sons, Inc

[18] Lars G. Sandberg 1978, Banking and Economic Growth in Sweden before World War I, The Journal of Economic History 38 (3): $650-680$

[19] Loan Rus. (2015), Technologies and Methods for Auditing Databases, Procedia Economics and Finance 26: 991-999

[20] Massood Samii and Gerald Karush. (2004), International Business and Information Technology, Routledge Taylor \& Francis Group

[21] Nurten Erdogan and Sezen Uludag. (2014), Comparison of Analysis Performed By Classical Approach and Bayesian Approach in Auditors' Decision Making Process: ProcediaSocial and Behavioral Sciences 150: 668-677
[22] Ol'ga Ponisciakova, Martina Gogolova and Katarina Ivankova. (2015), The Use of Accounting Information System for the Management of Business Costs, Procedia Economics and Finance 26: 418-422

[23] Philip Arestis, Panicos O. Demetriades and Kul B. Luintel2001, Financial Development and Economic Growth: The Role of Stock Markets, Journal of Money, Credit and Banking 33(1): 16-41

[24] Robert Hauswald and Robert Marquez 2003, Information Technology and Financial Services Competition, The Review of Financial Studies 16(3): 921-948

[25] Rupa Rege Nitsure 2003, 2004, E-Banking: Challenges and Opportunities, Economic and Political Weekly38 (51, 52): 5377-5381

[26] Vadlamani Ravi 2008, Advances in Banking Technology and Management: impacts of ICT and CRM? Information Science Reference Hershey. New York

[27] Vary T. Coates 1992, The Future of Information Technology, The Annals of the American Academy of Political and Social Science 522: 45-56

[28] Victoria Chiu, Qi Liu and Miklos A. Vasarhelyi. (2014), The Development and Intellectual Structure of Continuous Auditing Research, Journal of Accounting Literature 33: 3757

[29] William G. Gouge 1968, A Short History of Money and Banking, Augustus M. Kelley Publishers New York 